\title{
A Facile Platform for Photocatalytic Reduction of Methylene Blue Dye By CdSe-TiO 2 Nanoparticles
}

\author{
Irshad Ahmad Mir ${ }^{1} \cdot$ Inderjeet Singh $^{2} \cdot$ Balaji Birajdar $^{2} \cdot$ Kamla Rawat $^{2,3}{ }^{(D)}$
}

Received: 24 November 2016/Accepted: 15 May 2017 /Published online: 8 June 2017

(C) Springer Science+Business Media Singapore 2017

\begin{abstract}
Herein, we report on the demonstration of enhanced photocatalytic reduction of methylene blue (MB) dye using a physical mixture ( $w / w$ ratio: 50:1-9) of $\mathrm{TiO}_{2}$ nanoparticles (size $\approx 20 \pm 1 \mathrm{~nm}$ ) and CdSe nanocrystals (size $\approx 3.0 \pm 0.2 \mathrm{~nm}$ ). It was found that at the highest content of the nanocrystals $(9 \mathrm{mg})$ in the physical mixture, $67 \%$ reduction in the dye concentration could be achieved in a period of $60 \mathrm{~min}$ to prepare a physical mixture. Nanocatalyst characterization was accomplished using XRD, SEM, FTIR, UV-visible and Raman spectroscopy. The results showed that the prepared nanocatalyst could remove MB dye from waste water under the presence, as well as in the absence of UV- irradiation, while pristine $\mathrm{TiO}_{2}$ nanoparticles or the CdSe nanocrystals did not possess sufficient photocatalytic activity in the absence of UV-radiation. It is concluded that presence of $\mathrm{CdSe}$ nanocrystals at a mass concentration of less than $5 \%$ can be used for the remediation of water polluted with industrial dyes.
\end{abstract}

Keywords Titanium dioxide $\cdot$ Cadmium selenide $\cdot$

Nano-catalyst $\cdot$ Photo-catalysis $\cdot$ Dye reduction $\cdot$ Water remediation

Kamla Rawat

kamla.jnu@gmail.com

1 School of Physical Sciences, Jawaharlal Nehru University, New Delhi 110067, India

2 Special Center for Nanosciences, Jawaharlal Nehru University, New Delhi 110067, India

3 Inter University Accelerator Centre, New Delhi 110067, India

\section{Introduction}

Nanomaterials possess remarkable physicochemical properties due to which they have received much attention from researchers from different areas of science and engineering, including bioremediation. Bioremediation allows a fairly good clean-up protocol for non-toxic treatment of certain types of waste. However, it does not provide solutions for all waste management situations. Bioremediation cannot always offer a feasible strategy at sites infested with high concentration of toxic chemicals and other pollutants, which may include heavy metals, dyes and phenolic compounds. Furthermore, the advancement in science and technology has increased standard of living which directly or indirectly contributes to the increase in waste and toxic material. Therefore, the remediation of contaminants by use of existing technology is often not effective and efficient in cleaning up the environment. In this paper, we have used a physical mixture of two nanomaterials $\left(\mathrm{TiO}_{2}\right.$ and $\left.\mathrm{CdSe}\right)$ that have been individually used so far in bioremediation of waste water containing organic dyes [1].

Several studies have reported on the photocatalytic degradation of chemicals like organic compounds (2-chlorophenol, 4-chlorophenol) using $\mathrm{TiO}_{2}$ nanoparticles [2] and CdSsensitized $\mathrm{TiO}_{2}$ [3]. The photo-assisted oxidation of pentachlorophenol in $\mathrm{TiO}_{2}$ nanoparticle suspension has been investigated [4]. An extensive investigation performed on photocatalytic degradation of pentachlorophenol in aqueous solution utilizing immobilized $\mathrm{TiO}_{2}$ has been reported $[5,6]$. Recent investigations have shown the effect of transition metal ions doped in $\mathrm{TiO}_{2}$ on the photo-degradation of 4-nitrophenol. Wolf et al. have observed improvement in $\mathrm{W}^{5+}-\mathrm{TiO}_{2}$ nanoparticle system in the photocatalytic degradation of 1 , 4-dichlorophenol [7]. 
Apart from $\mathrm{TiO}_{2}$ nanoparticles (NPs), bismuth silicates under xenon lamp irradiation have successfully been used to degrade the pentachlorophenol largely mediated by superoxide radical $\left(\mathrm{O}_{2}-\right)$ [8]. Incorporation of transition metal ions into $\mathrm{TiO}_{2}$ is known to enhance the lifetime of photogenerated oxidation and reduction equivalents. It has been conceptualized that transition metal ions incorporated in semiconductor materials are oxidized and/or reduced by the conduction band electrons [9]. For instance, $\mathrm{UV}$-irradiated $\mathrm{TiO}_{2}-$ $\mathrm{Fe}^{3+}$ nanoparticles enhanced the EPR signal [10]. In addition, $\mathrm{Fe}^{3+}$ and $\mathrm{Cu}^{2+}$ ions were found to inhibit electron-hole recombination [11], whereas $\mathrm{Cr}^{3+}$ increased the recombination process [12]. The aforesaid results motivated the present work which is aimed at the design of novel nanomaterials either through physical or chemical blending to propose a facile platform for water remediation.

\section{Materials and Methods}

\section{Synthesis}

Synthesis of CdSe The details of synthesis CdSe quantum dot (QD) at room temperature has been discussed elsewhere [13]. In the procedure of CdSe quantum dots synthesis, we prepared $\mathrm{Cd}$ stock solution and reacted it with NaHSe solution at room temperature $\left(20^{\circ} \mathrm{C}\right)$. In this procedure, $0.2012 \mathrm{~g}$ of $\mathrm{CdCl}_{2} \cdot \mathrm{H}_{2} \mathrm{O}(20 \mathrm{mmol})$ was dissolved in $100 \mathrm{ml}$ of deionized water, followed by the addition of $400 \mu$ l of 3-MPA. The $\mathrm{pH}$ of the solution was maintained at 11 by the addition of $1.0 \mathrm{M}$ of $\mathrm{NaOH}$ solution. This solution was then reacted with $\mathrm{NaHSe}$ solution at room temperature. The later was prepared by reacting selenium $(40 \mathrm{mmol} / 0.0632 \mathrm{~g})$ with $\mathrm{NaBH}_{4}$ $(80 \mathrm{mmol} / 0.0636 \mathrm{~g}$ ) under stirring for $1 \mathrm{~h}$. This mixture was further stirred for $60 \mathrm{~min}$, and a clear yellow CdSe dispersion was obtained.

Synthesis of $\mathrm{TiO}_{2} \mathrm{TiO}_{2}$ nanoparticles were prepared by economical non-hydrolytic sol-gel route [14]. Ten millilitre of titanium tetra-isopropoxide (Spectrochem, India) was added to $40 \mathrm{ml}$ of 2-methoxy ethanol (SRL Chemical, India) used as solvent and magnetically stirred at room temperature with addition of few drops of $1.0 \mathrm{M} \mathrm{HNO}_{3}$ to maintain the $\mathrm{pH}$ value at 3 . The solution was maintained under stirring which resulted in gel formation, which was dried under infrared lamp followed by pulverization to generate an amorphous powder. To obtain crystalline anatase phase, amorphous powder was calcined at $450{ }^{\circ} \mathrm{C}$ for $1 \mathrm{~h}$ under ambient condition.

\section{Characterization}

Information about the morphology, crystal structure and average particle size of CdSe and $\mathrm{TiO}_{2}$ nanomaterial was obtained from transmission electron microscope (TEM) images, taken at $200 \mathrm{kV}$ (JEOL 2100F, field emission with magnification of $150,000 \times$ ). The samples used for $\mathrm{CdSe}-\mathrm{TiO}_{2} \mathrm{TEM}$ analysis were prepared as follows. A suitable amount of the nanomaterials of $\mathrm{CdSe}$ and $\mathrm{TiO}_{2}$ were taken separately, and as a well mixture of the two was dispersed in a given volume of deionized water which was ultrasonicated at room temperature for $5 \mathrm{~min}$. Then, a drop of the dispersion was spread over a 200 mesh copper grid with perforated carbon film and air dried at room temperature $\left(20^{\circ} \mathrm{C}\right)$ for 1 day.

Dynamic light scattering (DLS) experiments were conducted using a 256-channel digital correlator (Photocor Instruments, USA) used in the multi- $\tau$ mode (logarithmically spaced channels) at scattering angle of $\theta=90^{\circ}$ and using a laser of wavelength of $\lambda=632.8 \mathrm{~nm}$. The details of the instrument can be found elsewhere [15]. The correlator measures the intensity function $g_{2}(\tau)$ from which the relaxation time is deduced. The translational diffusion coefficient $\mathrm{D}$, determined from the relaxation time, is related to apparent hydrodynamic radius $R_{\mathrm{h}}$ through the Stokes-Einstein relation given by

$D=\frac{k_{B} T}{\left(6 \pi \eta_{0} R_{h}\right)}$

where the solvent viscosity, absolute temperature and Boltzmann constant are given by $\eta_{0}, T$ and $k_{B}$, respectively.

Scanning electron microscopy (SEM) images were obtained using EVO, 40 ZEISS, SEM Instrument to analyse surface morphology. The compositions and purity of nanocrystals was determined from the energy dispersive analysis of $\mathrm{X}$-rays (EDAX). UV-visible absorption spectra were recorded on UV-visible spectrophotometer (T90+ UV-visible spectrometer, UK). X-Ray diffraction (XRD) experiments were performed on a Rigaku D/Max 2200 diffractometer using $\mathrm{CuK}_{\alpha}$ radiation $(\lambda=1.5406 \AA)$. The details of the instrument can be found elsewhere [16].

\section{Photocatalytic Activity}

The photocatalytic activity of pristine $\mathrm{TiO}_{2}, \mathrm{CdSe}$ and physical mixture of $\mathrm{TiO}_{2}-\mathrm{CdSe}$ was spectroscopically analysed to note the degradation of methylene blue (MB) dye under UV light exposure. The reactions were carried out in a glass beaker containing $100 \mathrm{ml}$ dye solution (10 ppm or $10 \mathrm{mg} / \mathrm{L}$ ) and the required amount of nanomaterial. This aqueous suspension was kept under constant stirring and was irradiated with UV light of wavelength 254-365 nm (Osram ultra-vitalux, $300 \mathrm{~W}$ ) for time duration of 150 mins. After regular time intervals of $15 \mathrm{mins}, 3 \mathrm{ml}$ of dye solution is withdrawn, and its concentration was measured by recording the absorbance corresponding to $\lambda \approx 664 \mathrm{~nm}$. 


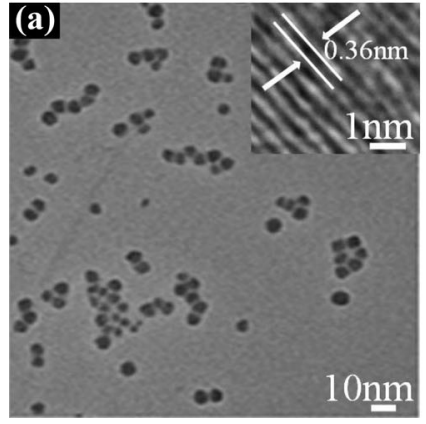

Fig. 1 TEM image of a CdSe QDs shows average size $3.0 \pm 0.2 \mathrm{~nm}$ and inset HRTEM, b clusters $\mathrm{TiO}_{2}$ with average size $20.0 \pm 1.0 \mathrm{~nm}$ and inset HRTEM c physical mixture of $\mathrm{CdSe}$ and $\mathrm{TiO}_{2}$ with inset HRTEM. Note
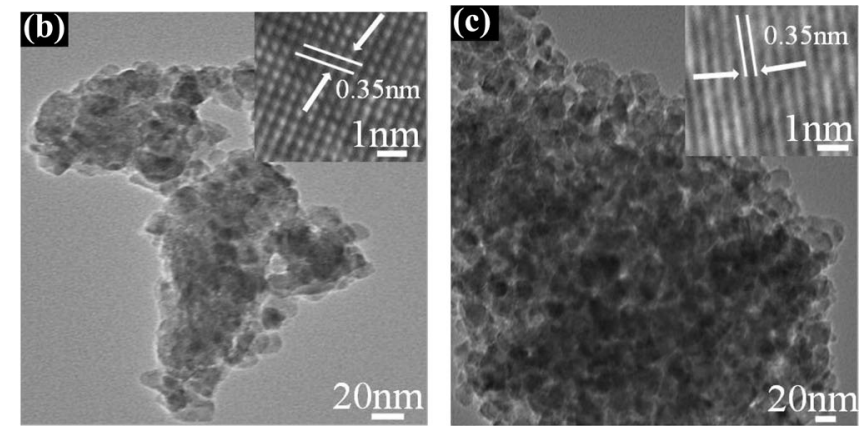

that TEM of $\mathrm{CdSe}-\mathrm{TiO}_{2}$ does not show the presence of CdSe because of large size of $\mathrm{TiO}_{2}$ clusters

relatively homogeneous and compact structure of the nanoparticles. The corresponding EDAX measurement (Fig. 3c, d) shows the major elemental compositions of $\mathrm{CdSe}$ were $\mathrm{Cd}$ and $\mathrm{Se}$, and of $\mathrm{TiO}_{2}$ were $\mathrm{Ti}$ and $\mathrm{O}$. The chemical composition was estimated to be $\mathrm{Cd}_{3.79} \mathrm{Se}_{4.04}$ and $\mathrm{Ti}_{8} \mathrm{O}_{2}$. In addition, the EDX results revealed that the chemical composition of the $\mathrm{CdSe}$ QDs is slightly decreased in content of Se compared to that of the original elemental ratio of $\mathrm{CdSe}_{2}$. It is to be noted that, qualitatively, EDX analysis confirmed the presence of constituent elements in $\mathrm{CdSe}$ and $\mathrm{TiO}_{2}$ samples.

\section{Optical Properties}

UV-visible absorption spectroscopy is an extremely useful analytical tool for monitoring optical properties of nanocrystal. As a result of quantum confinement and band-edge energy in semiconductor nanocrystals, the first exciton peak detected by static absorption can be used to determine the band-edge energy. As shown (Fig. 2b), the first absorption peak for CdSe QDs was at $\lambda_{\max } \approx 420 \mathrm{~nm}$ and for $\mathrm{TiO}_{2}$, it was at $400 \mathrm{~nm}$.
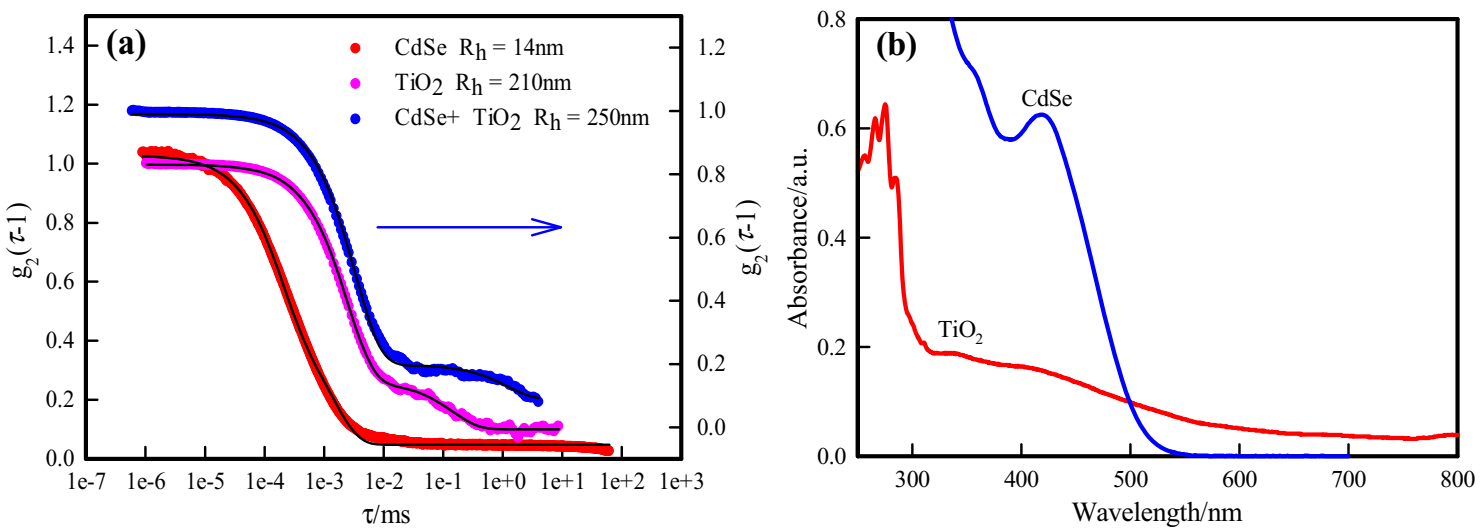

Fig. 2 a Hydrodynamic radius $R_{\mathrm{h}}$ of CdSe quantum dots $\left(R_{\mathrm{h}}=14 \mathrm{~nm}\right), \mathrm{TiO}_{2} \mathrm{NPs}\left(R_{\mathrm{h}}=210 \mathrm{~nm}\right)$ and $\mathrm{CdSe}-\mathrm{TiO}_{2}$ mixture $\left(R_{\mathrm{h}}=250 \mathrm{~nm}\right)$ determined from the correlation function. b Absorption spectra of $\mathrm{CdSe}$ and $\mathrm{TiO}_{2}$ nanocrystals. Note $\mathrm{CdSe}-\mathrm{TiO}_{2}$ mixture had the same absorbance spectra as that of $\mathrm{TiO}{ }_{2}$ 
Table 1 Comparison of physical properties of CdSe nanocrystals and $\mathrm{TiO}_{2}$ nanoparticles

\begin{tabular}{llll}
\hline Parameter & $\mathrm{TiO}_{2}$ & $\mathrm{CdSe}$ & Mixture \\
\hline Average core size/nm (TEM) & 15 & 3.0 & 15 \\
Cluster size/nm (DLS) & 210 & 14 & 250 \\
EDX composition $(\%$ atomic weight) & $\mathrm{Ti}_{8} \mathrm{O}_{2}$ & $\mathrm{Cd}_{3.79} \mathrm{Se}_{4.04}$ & $\mathrm{Ti}_{7} \mathrm{O}_{2}$ \\
Absorption peak $\left(\lambda_{\text {max }}\right) / \mathrm{nm}$ & 400 & 420 & 400 \\
\hline
\end{tabular}

\section{Crystalline Structure}

The XRD pattern (Fig. 4) of CdSe was considerably broadened due to very small size of the QDs. Pure anatase phase of $\mathrm{TiO}_{2}$ nanoparticles was confirmed with tetragonal symmetry. The XRD pattern exhibited prominent broad peaks at $2 \theta$ values of $25.2^{\circ}, 42.2^{\circ}$ and $49.4^{\circ}$ for $\mathrm{CdSe}$, and $25.5^{\circ}, 38.05^{\circ}, 48.20^{\circ}$, $54.16^{\circ}, 55.30^{\circ}, 62.90^{\circ}, 69.03^{\circ}, 70.46^{\circ}, 75.22^{\circ}$ and $80.08^{\circ}$ for $\mathrm{TiO}_{2}$ which were identified for cubic CdSe phase and tetragonal $\mathrm{TiO}_{2}$ phase. The respective dominant peaks represent reflections originating from (111), (220) and (311) planes for CdSe QDs and (101), (004), (105), (211), (204), (116), (220) and (110) for $\mathrm{TiO}_{2}$ nanoparticles, which is in agreement with JCPDS File No: 32-0483 [17]. The most intense peak at $2 \theta=25.2^{\circ}$ corresponding to (111) and at $2 \theta=25.5^{\circ}$ corresponding to (101) reflections (for $\mathrm{CdSe}$ and $\mathrm{TiO}_{2}$, respectively) was observed from the X-ray diffractogram, thus indicating preferred orientation along this direction. Using the Debye-Scherrer formula, the average crystallite size $\left(D_{\mathrm{x}}\right)$ was calculated.

$D_{\mathrm{x}}=\frac{k \lambda}{\beta \cos \theta}$ where $\beta$ is the full-width at half maximum (FWHM), $K$ is a constant known as the shape factor taken as 0.89 because of spherical shape of NPs, $\theta$ is the diffraction angle and $\lambda$ is the wavelength of X-ray radiation.

From the diffraction data, it was found that the QDs had crystallite size of $3.0 \mathrm{~nm}$, and these belong to the fcc phase with orientation in the (111) direction. Also, the crystallite size for pristine $\mathrm{TiO}_{2}$ nanoparticle was $15 \pm 2.0 \mathrm{~nm}$ corresponding to the tetragonal phase. XRD pattern did not show any additional peaks indicating the formation of pure and single phase. The calculated inter planar spacing determined from the reflection peak (111) was 3.53 and $3.49 \AA$ for CdSe nanocrystals and $\mathrm{TiO}_{2}$ nanoparticles, respectively. We found that $\mathrm{TiO}_{2}$ and $\mathrm{CdSe}-\mathrm{TiO}_{2}$ showed same crystal structure because of two reasons: (i) in the mixture, we have very low concentration of CdSe (3\% only) and (ii) $\mathrm{TiO}_{2}$ showed very high diffraction intensity compared to CdSe (Table 2).

\section{Photocatalytic Degradation of MB Dye}

The photocatalytic degradation of MB dye under UV irradiation without any catalyst showed absorption peak at $664 \mathrm{~nm}$. Figure 5a shows absorption spectra of UV irradiation (for $150 \mathrm{~min}$ ) for different prepared compositions of $\mathrm{CdSe}$ and $\mathrm{TiO}_{2}$. Clearly, we observe a significant decrease in absorbance intensity of MB in the presence of mixture of $\mathrm{CdSe}$ and $\mathrm{TiO}_{2}$ compared to individual constituents. It was found that $65 \% \mathrm{MB}$ dye degraded within $150 \mathrm{~min}$ in the presence of mixture $\left(50 \mathrm{mg} \mathrm{TiO}_{2}+9 \mathrm{mg} \mathrm{CdSe}\right)$ which is higher than that obtained from presence of CdSe QDs (10\%) and $\mathrm{TiO}_{2}$ nanoparticles (48\%). This suggests
Fig. 3 SEM image of a CdSe QDs and $\mathbf{b} \mathrm{TiO}_{2}$ nanoparticles shows clusters of $\mathrm{CdSe}$ and $\mathrm{TiO}_{2}$. EDAX plot of c CdSe QDs and d $\mathrm{TiO}_{2}$ nanomaterials showing the purity of the sample
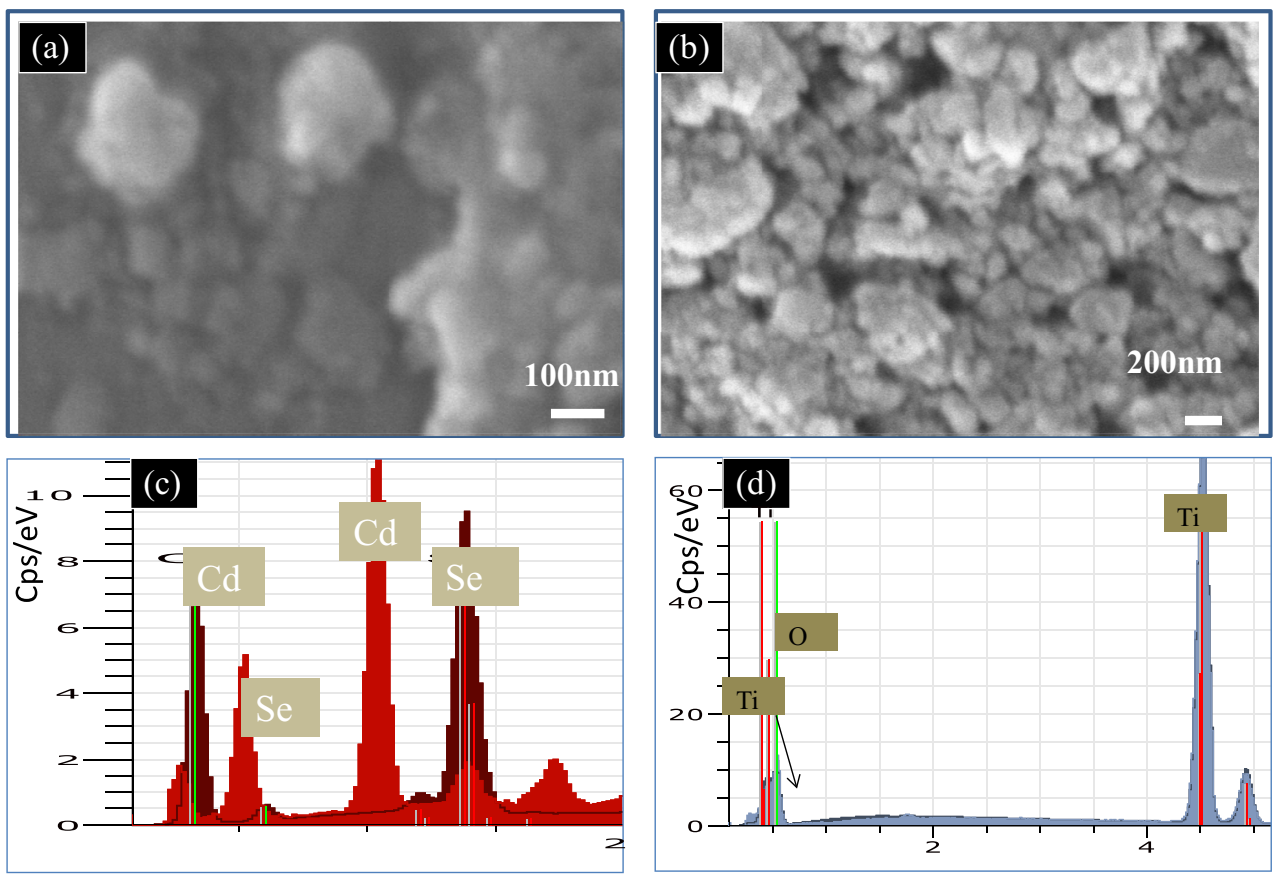


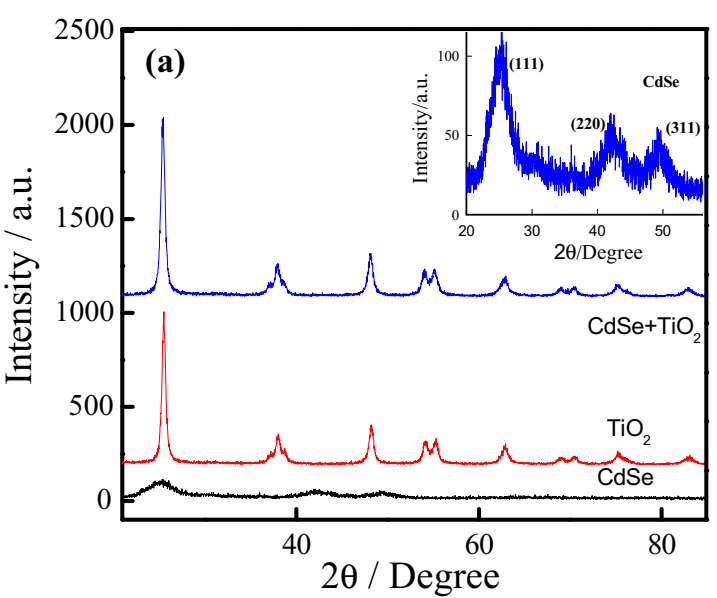

Fig. 4 a X-ray diffraction patterns of $\mathrm{CdSe}, \mathrm{TiO}_{2}$ and $\mathrm{CdSe}-\mathrm{TiO}_{2}$ (mixture) samples. From the analysis, we found the inter-planer spacing, $d=3.53$ and $3.49 \AA$, respectively for $\mathrm{CdSe}$ and $\mathrm{TiO}_{2}$. Inset shows XRD pattern of CdSe. Note that there is no apparent change in

CdSe- $\mathrm{TiO}_{2}$ blend was a more efficient catalyst for degradation of dye. In addition to this, we observed blue shift in maximum absorption wavelength of MB solution which increased with mass fraction of CdSe quantum dots in the mixture. This could be attributed to reduced absorbance value of the decomposed products. Figure $5 \mathrm{~b}$ shows plot of normalized concentration with time at maximum absorption wavelength for variable compositions of the mixture. This plot can be used to calculate rate constant $(k$, rate of degradation of dye), because photo-degradation process was fitted to pseudo first-order kinetics using the formula

$\mathrm{k}=\frac{\left\{\ln \left(\frac{\mathrm{C}_{0}}{\mathrm{C}}\right)\right\}}{\mathrm{t}}$

where $C_{0}$ is the maximum absorbance at time $t=0$ and $\mathrm{C}$ is the absorbance at time $t$.

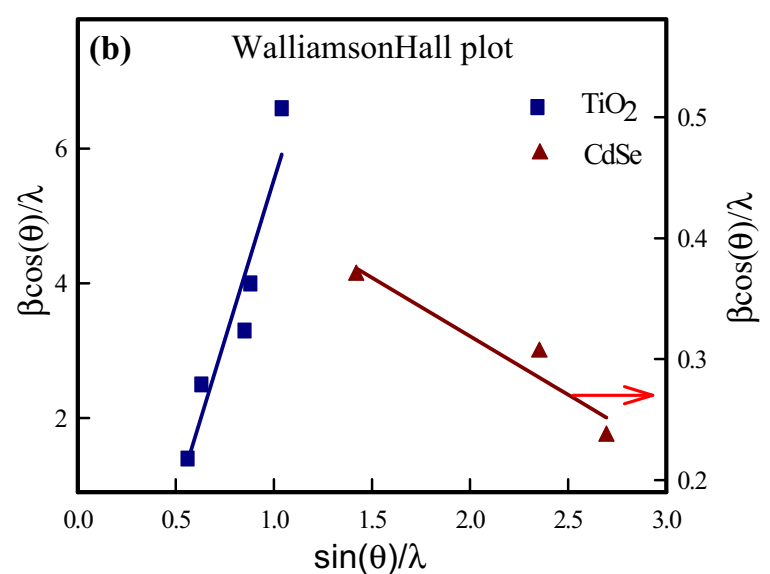

crystal structure of $\mathrm{CdSe}-\mathrm{TiO}_{2}$ (mixture), it is identical toTiO ${ }_{2}$. b Williamson-Hall plot gives more accurate average crystallite size, as $D_{\mathrm{x}}=3 \mathrm{~nm}$ for CdSe and $20 \mathrm{~nm}$ for $\mathrm{TiO}_{2}$ and the $\mathrm{CdSe}-\mathrm{TiO}_{2}$ mixture

Figure 6 shows the plot of rate constant $k$ as a function of $\%$ amount of CdSe quantum dots in the physical mixture of $\mathrm{TiO}_{2}$ nanopowder and $\mathrm{CdSe}$ quantum dots. The percentage amount of CdSe was calculated from

\%amount of CdSe

$$
=\frac{\text { Amount of } \mathrm{CdSe}}{\left(\text { Amount of } \mathrm{TiO}_{2} \text { nano-powder }+ \text { Amount of } \mathrm{CdSe}\right)}
$$

We found that $5.66 \%$ amount of $\mathrm{CdSe}$ with $\mathrm{TiO}_{2}$ gives a maximum rate constant $k$ value of $3.97 \times 10^{-3} \mathrm{~min}^{-1}$. The above results showed that increasing the amount of $\mathrm{CdSe}$ quantum dots had a direct and remarkable influence on the photocatalytic activity of $\mathrm{TiO}_{2}$ nanoparticles.

Coupling $\mathrm{TiO}_{2}$ with small band gap semiconductors has proven to be a milestone for improvement in photocatalytic activity. High density single crystalline $\mathrm{TiO}_{2} / \mathrm{CdSe}$ nanowires has been successfully grown on Ti substrate by chemical

Table 2 Different parameters calculated from XRD data of CdSe QDs and $\mathrm{TiO}_{2}$ nanoparticles. Note that $\mathrm{CdSe}^{-} \mathrm{TiO}_{2}$ mixture had parameters similar to that of $\mathrm{TiO}_{2}$

\begin{tabular}{|c|c|c|c|c|c|c|c|}
\hline & \multirow[t]{2}{*}{ Planes (hkl) } & \multirow[t]{2}{*}{$2 \theta$ (degree) } & \multirow{2}{*}{$\begin{array}{l}\text { FWHM } \\
\text { (degree) }\end{array}$} & \multirow{2}{*}{$\begin{array}{l}\text { Crystallite } \\
\text { size }(\mathrm{nm})\end{array}$} & \multicolumn{3}{|c|}{ Parameters from William-Hall plot } \\
\hline & & & & & Strain $\times 10^{-3}$ & $\begin{array}{l}\text { Density dislocation } \times \\
10^{16} \text { lines } / \mathrm{m}^{2}\end{array}$ & $\begin{array}{l}\text { Crystallite size } \\
(\mathrm{nm}) \mathrm{W}-\mathrm{H} \text { plot }\end{array}$ \\
\hline \multirow[t]{3}{*}{$\mathrm{CdSe}$} & $(111)$ & 25.20 & 3.84 & 2.10 & \multirow[t]{3}{*}{-24.19} & \multirow[t]{3}{*}{25.00} & \multirow[t]{3}{*}{3.02} \\
\hline & $(220)$ & 42.20 & 4.36 & 1.94 & & & \\
\hline & $(311)$ & 49.40 & 4.39 & 2.02 & & & \\
\hline \multirow[t]{5}{*}{$\mathrm{TiO}_{2}$} & $(101)$ & 25.51 & 0.51 & 16.0 & \multirow[t]{5}{*}{23.93} & \multirow[t]{5}{*}{0.25} & \multirow[t]{5}{*}{20.1} \\
\hline & (200) & 48.23 & 0.60 & 14.1 & & & \\
\hline & (204) & 62.85 & 0.88 & 11.2 & & & \\
\hline & $(215)$ & 75.34 & 0.99 & 10.2 & & & \\
\hline & (224) & 82.97 & 1.24 & 8.57 & & & \\
\hline
\end{tabular}




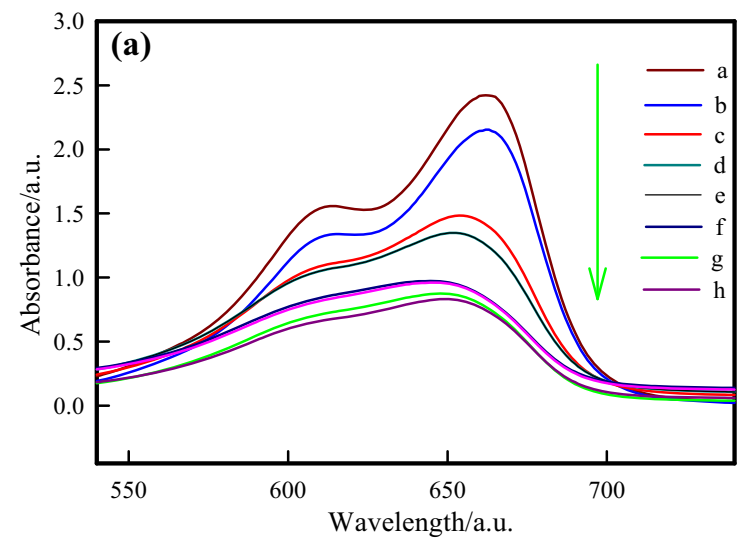

Fig. 5 a Absorbance spectra of MB solution after 150 min of UV irradiation and $\mathbf{b}$ normalized concentration plot with time for $\mathbf{a}$ without any catalyst; with b $5 \mathrm{mg} \mathrm{CdSe}$; $50 \mathrm{mg} \mathrm{TiO}{ }_{2}$; d $50 \mathrm{mg} \mathrm{TiO}{ }_{2}+1 \mathrm{mg}$

vapour deposition [18]. These nanowires were found to degrade MB dye completely within $80 \mathrm{~min}$ of UV irradiation. Cardiel et al. reported [19] $\mathrm{TiO}_{2}-\mathrm{WO}_{3}$ composite for $\mathrm{MB}$ dye degradation with highest $k$ value of $2.7 \times 10^{-3} \mathrm{~min}^{-1}$ was achieved, which was found to be less than our reported $k$ value of $3.97 \times 10^{-3} \mathrm{~min}^{-1}$. CdS and CdSe nanoparticle deposited on ordered $\mathrm{TiO}_{2}$ nanotubes [20] were found to efficiently degrade methylene orange dye (up to 95\%) within $120 \mathrm{~min}$ of visible light irradiation. Ninety percent $\mathrm{MB}$ dye degradation was achieved in the presence of visible light by $\mathrm{TiO}_{2} / \mathrm{CuS}$ composite nanostructure, synthesized via surface functionalization route [21]. In all the above-mentioned reports, there was a requirement of integrating $\mathrm{TiO}_{2}$ with semiconductors into a single nanoscale heterostructure, which in itself requires extensive synthesis. But our method avoids this step and shows that a physical blend of $\mathrm{TiO}_{2}$ with $\mathrm{CdSe}$ can efficiently degrade the organic pollutant present commonly in effluents from textile industries.

\section{Photo-Catalytic Activity and Mechanism}

The photocatalytic activity of $\mathrm{TiO}_{2}$ arises due to production of electron-hole pair by absorbing energy either greater than

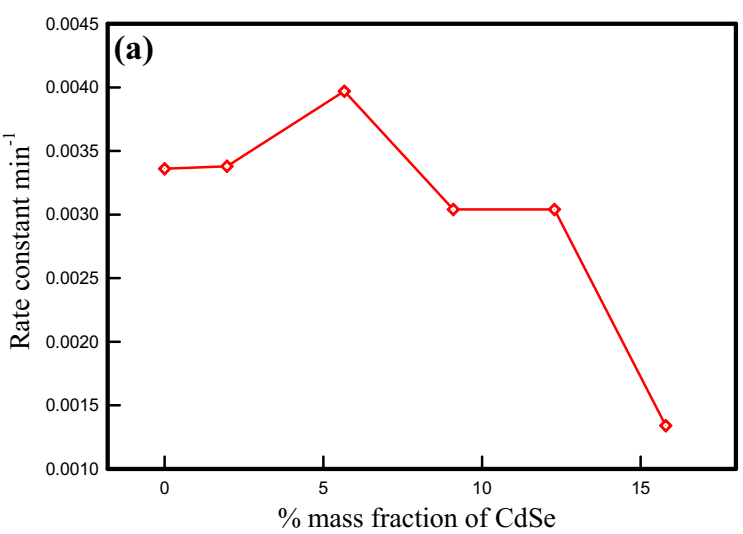

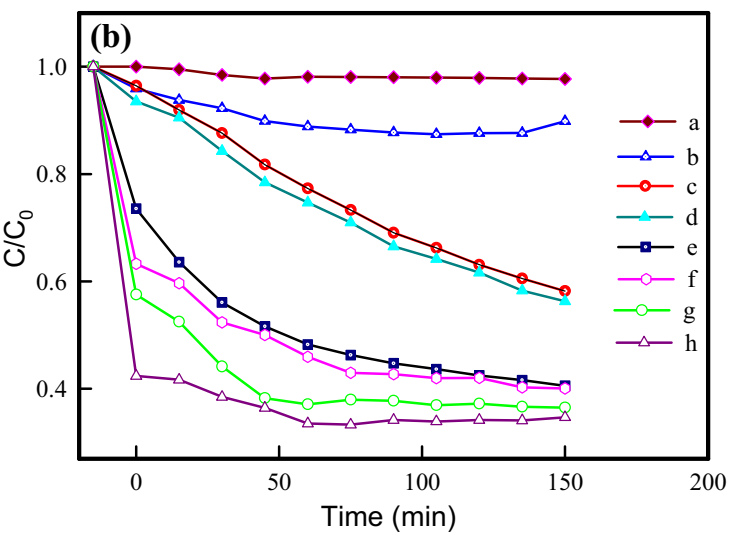

CdSe; e $50 \mathrm{mg} \mathrm{TiO}{ }_{2}+3 \mathrm{mg} \mathrm{CdSe} ; \mathbf{f} 50 \mathrm{mg} \mathrm{TiO}{ }_{2}+5 \mathrm{mg} \mathrm{CdSe} ; \mathbf{g} 50 \mathrm{mg}$

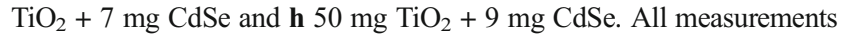
were done at room temperature $\left(20^{\circ} \mathrm{C}\right)$

or equal to energy gap. The electron being produced is promoted to conduction band, and hole remains in valence band. These electron hole pair may recombine or dissipate some energy to reach metastable states. The electron in metastable state interacts with oxygen vacancies to generate superoxide ions, whereas the hole (in the metastable state) interacts with adsorbed $\mathrm{H}_{2} \mathrm{O}$ or $\mathrm{OH}^{-}$ions at the catalystwater interface to form highly reactive hydroxyl radicals. These highly active oxygen species oxidize organic pollutants into simple $\mathrm{CO}_{2}$ and $\mathrm{H}_{2} \mathrm{O}$ molecules. To enhance photocatalytic activity of $\mathrm{TiO}_{2}$ significant amounts of dopants were used in recent years. Further each one required UV or visible light irradiation for activation. It would be interesting to explore the efficacy of modified $\mathrm{TiO}_{2}$ nanostructure that does not require any light.

It was found that all $\mathrm{CdSe}-\mathrm{TiO}_{2}$ samples exhibited enhanced photo-degradation activity compared to bare $\mathrm{TiO}_{2}$ nanoparticles. This accounts for photocatalytic activation of CdSe QDs. In the absence of light, thermally generated electrons in conduction band of CdSe may tunnel to conduction band of $\mathrm{TiO}_{2}$ and react with $\mathrm{O}_{2}$ to form reactive oxygenspecies (ROS), whose number increase with CdSe content,

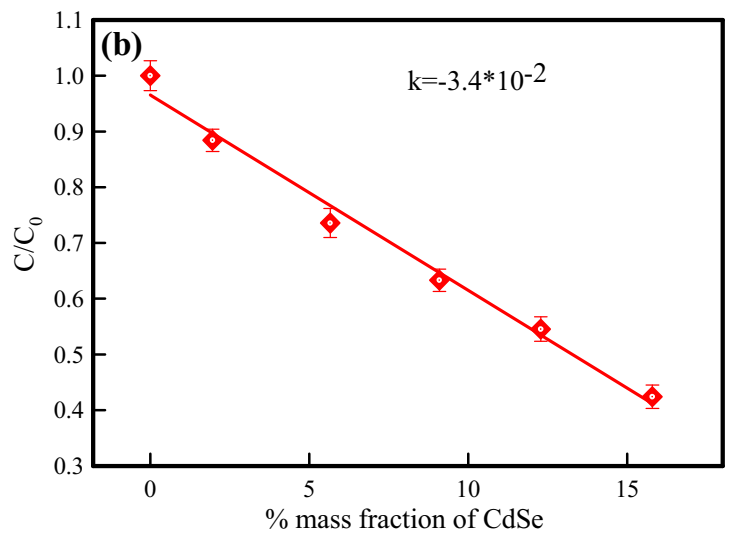

Fig. 6 a Rate constant, $k$ as function of percentage mass fraction of CdSe quantum dot in physical mixture of $\mathrm{TiO}_{2}$ and $\mathrm{CdSe}$. $\mathbf{b}$ Normalized concentration without using any source of illumination with percentage mass fraction of CdSe quantum dot in physical mixture of TiO ${ }_{2}$ and $\mathrm{CdSe}$ 
Fig. 7 Schematic diagram of the photocatalytic reaction of $\mathrm{MB}$ on $\mathrm{TiO}_{2} / \mathrm{CdSe}$

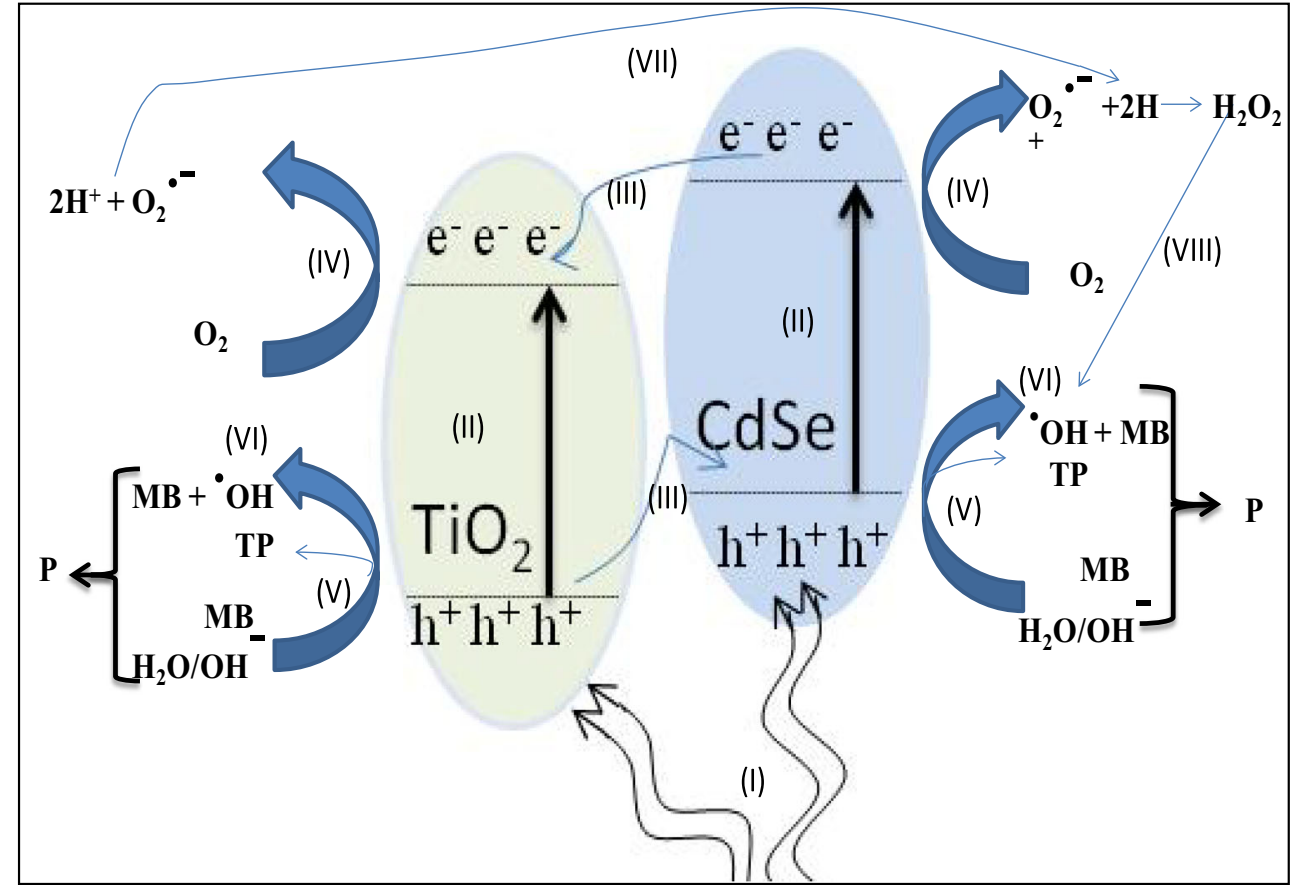

and therefore may be responsible for enhanced degradation efficiency.

It is widely accepted that generation and separation of electron-hole pairs is necessary for the photocatalytic action of semiconductors [22]. The proposed mechanism of MB dye degradation by the nanocomposite photocatalyst is discussed in numbered steps in Fig. 7. When $\mathrm{TiO}_{2}$ is irradiated with light of energy equal to or greater than the Fermi gap energy, an electron-hole pair is produced on the surface of $\mathrm{TiO}_{2}$. When the nanocomposite system is illuminated ( $\mathrm{I}$ in Fig. 7) with the UV light, both $\mathrm{TiO}_{2}$ and $\mathrm{CdSe}$ are activated and generate $\mathrm{e}^{-}$ and $\mathrm{h}^{+}$in their respective conduction and valence bands (II in Fig. 7).

$C d S e+\mathrm{hv} \rightarrow C d S e\left(\mathrm{e}^{-}+\mathrm{h}^{+}\right)$

The electrons in the $\mathrm{CB}$ of CdSe migrate across the interfacial boundary to the $\mathrm{CB}$ of $\mathrm{TiO}_{2}$. Likewise, the holes generated in the valence band of $\mathrm{TiO}_{2}$ migrate to the $\mathrm{VB}$ of $\mathrm{CdSe}$. The migration of generated opposite charge facilitates charge carrier separation (III) and thus reduces recombination rate $[23,24]$.

$C d S e\left(\mathrm{e}^{-}\right)+\mathrm{TiO}_{2} \rightarrow C d S e+\mathrm{TiO}_{2}\left(\mathrm{e}^{-}\right)$

This ensures higher propensity of surface charge with significantly long lifetimes to participate in redox reaction. This imparts enhanced photocatalytic activity to the blend compared to their individual contributions. The transferred electrons in the active sites of $\mathrm{TiO}_{2}$ react with adsorbed $\mathrm{O}_{2}$ to form super-oxides $\left(\mathrm{O}_{2}{ }^{-}\right)$. This superoxide reacts with hydrogen ion to form $\mathrm{H}_{2} \mathrm{O}_{2}$ and decomposes to generate hydroxyl radicals
$(O \dot{H})$ [25]. These radicals have strong oxidation potential to degrade the dye. The reactions are given by

$\mathrm{TiO}_{2}\left(\mathrm{e}^{-}\right)+\mathrm{O}_{2} \rightarrow \mathrm{TiO}_{2}+\mathrm{O}^{2-}$

$\mathrm{O}_{2}^{-}+\mathrm{H}^{+} \rightarrow \mathrm{HO}_{2}$

$\mathrm{HO}_{2} \times+\times . \mathrm{O}_{2}^{-}+\mathrm{H}^{+} \rightarrow \mathrm{H}_{2} \mathrm{O}_{2}+\mathrm{O}_{2}$

$\mathrm{H}_{2} \mathrm{O}_{2}+\cdot \mathrm{O}_{2}^{-} \rightarrow \cdot \mathrm{OH}^{+}+\mathrm{OH}^{-}+\mathrm{O}_{2}$ or $\quad \mathrm{H}_{2} \mathrm{O}_{2}+\mathrm{e}^{-} \rightarrow \mathrm{OH}^{-}+\cdot \mathrm{OH}$

$\mathrm{OH}+$ dye $\rightarrow$ oxidation products

The positively charged hole $\left(\mathrm{h}^{+}\right)$reacts with $\mathrm{OH}^{-}$or $\mathrm{H}_{2} \mathrm{O}$ adsorbed to the surface of $\mathrm{TiO}_{2}$ to generate hydroxyl radicals [26].

$\mathrm{CdSe}\left(\mathrm{h}^{+}\right)+\mathrm{H}_{2} \mathrm{O} \rightarrow \mathrm{H}^{+}+\mathrm{CdSe}+\cdot \mathrm{OH}$

The bulk hydroxyl radicals generated through the superoxide route and the trapped holes route react with any MB transformation products (TP) and the remaining bulk MB to produce simpler molecules (VIII).

\section{Conclusion}

Herein, we report the demonstration of photocatalytic reduction of MB dye using a physical mixture of nanoparticles and nanocrystals $\left(\mathrm{TiO}_{2}-\mathrm{CdSe}\right)$ in the $(w / w)$ ratio: 50:1-9. It was found that at the highest content of the nanocrystals ( $9 \mathrm{mg}$ ), $67 \%$ of reduction in the dye concentration could be achieved in a period of $60 \mathrm{~min}$. It is concluded that the presence of $\mathrm{CdSe}$ nanocrystals at a mass concentration less than $5 \%$ can be used 
for remediation of water polluted with industrial dyes. The most interesting conclusion is that physical blend of nanomaterials can exhibit catalytic property superior to their individual contributions.

Acknowledgements IAM acknowledges the University Grants Commission, Government of India for Research Fellowship. IS acknowledges the receipt of Junior Research Fellowship from university grant commission (UGC), Government of India. KR is thankful to the Department of Science and Technology, Government of India for Inspire Faculty Award. We are thankful to the Advanced Research Instrumentation Facility of the University for allowing us access the SEM facility.

\section{References}

1. Lakshmi S, Renganathan R, Fujita S (1995) Study on $\mathrm{TiO}_{2}$-mediated photocatalytic degradation of methylene blue. J Photochem Photobiol A Chem 88:163-167

2. Stafford U, Gray KA, Kamat PV (1996) Photocatalytic degradation of organic contaminants: Halophenols and related model compounds. Heterog Chem Rev 3:77-104

3. Serpone N, Maruthamuthu P, Pichat P, Pelizzetti E, Hidaka H (1995) Exploiting the interparticle electron transfer process in the photocatalysed oxidation of phenol, 2-chlorophenol and pentachlorophenol: chemical evidence for electron and hole transfer between coupled semiconductors. J Photochem Photobiol A Chem 85:247-255

4. Mills G, Hoffmann MR (1993) Photocatalytic degradation of pentachlorophenol on titanium dioxide particles: identification of intermediates and mechanism of reaction. Environ Sci Technol 27: 1681-1689

5. Gunlazuardi J, Lindu WA (2005) Photocatalytic degradation of pentachlorophenol in aqueous solution employing immobilized $\mathrm{TiO}_{2}$ supported on titanium metal. J Photochem Photobiol A Chem 173:51-55

6. Paola AD, Marci G, Palmisano L, Schiavello M, Uosaki K, Ikeda S, Ohtani B (2002) Preparation of polycrystalline $\mathrm{TiO}_{2}$ photocatalysts impregnated with various transition metal ions: characterization and photocatalytic activity for the degradation of 4-nitrophenol. J Phys Chem B 106:637-645

7. Subramanian V, Wolf E, Kamat PV (2001) Semiconductor-metal composite nanostructures. To what extent do metal nanoparticles improve the photocatalytic activity of $\mathrm{TiO}_{2}$ films? J Phys Chem B 105:11439-11446

8. Li Y, Niu J, Yin L, Wang W, Bao Y, Chen J, Duan Y (2011) Photocatalytic degradation kinetics and mechanism of pentachlorophenol based on superoxide radicals. J Environ Sci 23:1911-1918

9. Linsebigler AL, Lu G, Yates JT (1995) Photocatalysis on $\mathrm{TiO}_{2}$ surfaces: principles, mechanisms, and selected results. Chem Rev 95:735-758

10. Gratzel M, Howe RF (1990) Electron paramagnetic resonance studies of doped titanium dioxide colloids. J Phys Chem 94:2566-2572
11. Butler EC, Davis AP (1993) Photocatalytic oxidation in aqueous titanium dioxide suspensions: the influence of dissolved transition metals. J Photochem Photobiol A Chem 70:273-283

12. Herrmann JM, Disdier J, Pichat P (1984) Effect of chromium doping on the electrical and catalytic properties of powder titania under UV and visible illumination. Chem Phys Lett 108:618-622

13. Mir IA, Das K, Rawat K, Bohidar HB (2016) Hot injection versus room temperature synthesis of CdSe quantum dots: a differential spectroscopic and bioanalyte sensing efficacy evaluation. Colloids Surf A Physicochem Eng Asp 494:162-169

14. Wang E, Yang W, Cao Y (2009) Unique surface chemical species on indium doped $\mathrm{TiO}_{2}$ and their effect on the visible light photocatalytic activity. J Phys Chem C113:20912-20917

15. Rawat K, Bohidar HB (2012) Universal charge quenching and stability of proteins in 1-methyl-3-alkyl (hexyl/octyl) imidazolium chloride ionic liquid solutions. J Phys Chem B116:11065-11074

16. Mir IA, Rawat K, Bohidar HB (2016) CuInGaSe nanocrystals for detection of trace amount of water in D2O (at ppm level). Cryst Res Technol 51:561-568

17. JCPDS File No: 32-0483.

18. Lee JC, Kim TG, Choi HJ, Sung YM (2007) Enhanced photochemical response of $\mathrm{TiO}_{2} / \mathrm{CdSe}$ heterostructured nanowires. Cryst Growth Des 7:2588-2593

19. Cardiel AC, Benson MC, Bishop LM, Louis KM, Yeager JC, Tan Y, Hamers RJ (2012) Chemically directed assembly of photoactive metal oxide nanoparticle heterojunctions via the coppercatalyzedazide-alkyne cycloaddition "click" reaction. ACS Nano 6:310-318

20. Lv J, Wang H, Gao H, Xu G, Wang D, Chen Z, Zhang X, Zheng Z, Wu Y (2015) A research on the visible light photocatalytic activity and kinetics of $\mathrm{CdS} / \mathrm{CdSe}$ co-modified $\mathrm{TiO}_{2}$ nanotube arrays. Surf Coat Technol 261:356-363

21. Khanchandani S, Kumar S, Ganguli AK (2016) Comparative study of $\mathrm{TiO}_{2} / \mathrm{CuS}$ core/shell and composite nanostructures for efficient visible light photocatalysis. ACS Sustain Chem Eng 4:1487-1499

22. Liu H, Cheng SA, Wu M, Wu HJ, Zhang JQ, Li WZ, Cao CN (2000) Photoelectrocatalytic degradation of sulfosalicylic acid and its electrochemical impedance spectroscopy investigation. J Phys Chem A 104:7016-7020

23. Li W, Cui X, Wang P, Shao Y, Li D, Teng F (2013) Enhanced photosensitized degradation of rhodamine $\mathrm{B}$ on $\mathrm{CdS} / \mathrm{TiO}_{2}$ nanocomposites under visible light irradiation. Mater Res Bull 48: 3025-3031

24. Wang W, Wang J, Wang Z, Wei X, Liu L, Ren Q, Gao W, Liang Y, Shi $\mathrm{H}$ (2014) $\mathrm{P}-\mathrm{n}$ junction $\mathrm{CuO} / \mathrm{BiVO}_{4}$ heterogeneous nanostructures: synthesis and highly efficient visible-light photocatalytic performance. Dalton Trans 43:6735-6743

25. Li X, Xia T, Xu C, Murowchick J, Chen X (2014) Synthesis and photoactivity of nanostructured $\mathrm{CdS}-\mathrm{TiO}_{2}$ composite catalysts. Catal Today 225:64-73

26. Ghosh T, Lee JH, Meng ZD, Meng ZD, Ullah K, Park CY, Nikam V, Oh WC (2013) Graphene oxide based CdSe photocatalysts: synthesis, characterization and comparative photocatalytic efficiency of rhodamine B and industrial dye. Mater Res Bull 48:1268-1274 